\title{
Grupo Psicoeducativo de Radioterapia: Relato de Experiência
}

\author{
Santos, Vivian Teodoro dos; Duarte, Estela de Castro; Jorge, Laís Navarro; Oliveira, Janaína \\ Novaes de; Tonaki, Juliana Ono; Oliveira, Cinthia Greicim de \\ Instituto do Câncer do Estado de São Paulo (Icesp) — vivianteodoro@bol.com.br
}

\begin{abstract}
INTRODUÇÃO: a radioterapia é pouco conhecida por grande parte dos pacientes que iniciam esse tratamento, o que pode potencializar sentimentos de medo do desconhecido, desesperança, solidão e incerteza. Estes sentimentos foram constatados nas primeiras consultas de revisão semanal no setor de radioterapia. Frente a essa problemática e à dificuldade de compreensão por parte de alguns pacientes, observou-se a necessidade de realização de um grupo de orientação que atendesse a estas necessidades. o grupo esclarece a rotina do tratamento e oferece de forma humanizada um convívio de iguais onde descobrem que durante o tratamento poderão contar com os profissionais envolvidos no seu cuidado. OBJETIVO: Relatar como acontece o acolhimento dos usuários na radioterapia, que visa amenizar as ansiedades, incertezas e angústias e auxiliar na relação entre usuário e equipe multidisciplinar. MÉTODO: para formação do grupo de orientação, selecionaram-se aleatoriamente os pacientes que apresentavam lesões nas regiões de próstata, cabeça e pescoço e trato gastrointestinal. o convite para participação realizou-se por meio de contato telefônico. Após a confirmação de presença, os temas foram planejados de forma expositiva e participativa, por meio de álbum seriado com explicações do tratamento, fotos de acessórios e equipamentos utilizados, além de apresentar as equipes de apoio e multidisciplinar. o grupo dispunha-se em roda, oferecia aos participantes o direito de exposição de dúvidas e, ao final, solicitou-se o preenchimento da pesquisa de satisfação. RESULTADOS: de acordo com dados referentes a seis grupos realizados (1\%. semestre de 2011), observou-se que, dos pacientes selecionados, 50\% confirmaram a presença; desses, $24 \%$ compareceram. Dentre os motivos para as faltas e não confirmações de presença surgiram: falta de interesse, dificuldade financeira, falta de transporte, telefone de contato errado, paciente residente em outra cidade/estado, tentativa de contato sem sucesso, óbito e paciente transferido para o Núcleo Avançado de Cuidados Especiais. em relação à pesquisa de satisfação, verificou-se que $77 \%$ dos participantes acharam ótimo participar da atividade, $22 \%$ bom e $1 \%$ regular. Alguns sentimentos também foram mencionados pelos pacientes, como bem estar, segurança e experiência. Vale destacar o comentário de um paciente: "A concomitância da psicologia e enfermagem contribuíram à competência médica científica do Instituto do câncer, vocês estão de parabéns". CONCLUSÃO: Evidenciou-se a importância do grupo de apoio e acolhida, onde o paciente vivencia vários sentimentos, os quais poderão impedi-lo de realizar um tratamento e, muitas vezes, o levam a desistir por falta de orientação adequada. o grupo de orientação proporcionou a facilitação da adesão dos pacientes ao tratamento radioterápico e a participação no grupo propiciou aos pacientes certa estabilidade emocional frente ao tratamento e manejo das complicações, por melhor compreensão das orientações.
\end{abstract}

Santos, Vivian Teodoro dos; Duarte, Estela de Castro; Jorge, Laís Navarro; Oliveira, Janaína Novaes de; Tonaki, Juliana Ono; Oliveira, Cinthia Greicim de. Grupo Psicoeducativo de Radioterapia: Relato de Experiência. In: Anais do Congresso Internacional de Humanidades \& Humanização em Saúde [= Blucher Medical Proceedings, num.2, vol.1]. São Paulo: Editora Blucher, 2014. ISSN 2357-7282

DOI 10.5151/medpro-cihhs-10754 